\title{
Analisis Kontrol Aliran Fluida Bervikositas Tinggi dengan Sensor Flow YF-S201 pada Otomatisasi Dispenser Minyak Goreng
}

\author{
Hadi Supriyanto ${ }^{1}$, Abdur Rohman Harits Martawireja \\ ${ }^{1}$ Jurusan Otomasi Manufaktur dan Mekatronika, Politeknik Manufaktur Bandung \\ Email: 1hadi_s@polman-bandung.ac.id
}

\begin{abstract}
Abstrak
Abstrak-- Sistem Otomasi pada Dispenser Minyak Goreng Hygenist Automatic ini bertujuan untuk memudahkan pemasok/penjual minyak goreng dalam menakara minyak dengan baik, disamping meminimalisir kontaminasi pada minyak goreng. Dispenser ini dirancang menggunakan pompa minyak dan flowsensor yf-s201 untuk mengukur banyaknya minyak yang dikeluarkan. Control Valve / katup elektrik dengan delay digunakan untuk menjaga minyak dari kontaminasi sebagai pengganti kran manual. Penelitian ini fokus pada perancangan dan pembuatan sistem otomasi pada dispenser minyak goreng serta menghitung waktu dan ketepatan dari volume yang dikeluarkan oleh dispeser. Dispenser dibuat mobile (dapat dipindahkan), mampu menampung $50 \mathrm{Kg}$ minyak goreng dan memiliki dua pilihan takaran yakni 500ml dan 250ml. Dari hasil percobaan didapatkan pembacaan flowsensor menunjukkan hasil frekuensi rata-rata yang sama yaitu sebesar $35 \mathrm{~Hz}$ untuk pengisian $500 \mathrm{~mL}$ dan $25 \mathrm{~Hz}$ untuk pengisian minyak $250 \mathrm{~mL}$. Waktu yang diperlukan untuk mengeluarkan minyak $250 \mathrm{~mL}$ dari dispenser sebesar 8,85 s dan 15,3 s untuk mengeluarkan minyak $500 \mathrm{~mL}$. Dengan program delay dapat diperbaki nilai keluaran minyak, untuk volume target $250 \mathrm{~mL}$ diperlukan delay sebesar 5,75 s dan untuk volume targer keluaran $500 \mathrm{~mL}$ diperlukan delay sebesar $12 \mathrm{~s}$.
\end{abstract}

Kata Kunci: Flowsensor YF-S201, Pompa DC, Control Valve

\begin{abstract}
The purpose of Automation system on the Hygenist Automatic Frying Oil Dispenser making is to assist the frying oil sellers or suppliers in measuring the oil accurately and minimize the frying oil contamination. The dispenser is designed using pump and flowsensor to measure the frying oil pumped out. Electric valve or faucet is used to prevent contamination of the oil as the substitute of manual faucet. This study is focused on designing and making automation system on the frying oil dispenser, measuring time and volume accuracy of dispenser. Dispensers can be moved, capable of accommodating $50 \mathrm{Kg}$ of oil and have a choice of two quantities; $500 \mathrm{ml}$ and $250 \mathrm{ml}$. As a result, flowsensor reading shows the same average frequency of $25 \mathrm{~Hz}$ and 35 $\mathrm{Hz}$ for filling $250 \mathrm{~mL}$ oil and $500 \mathrm{~mL}$ respectively. Time consumption for pumping $250 \mathrm{~mL}$ and $500 \mathrm{~mL}$ oil out from the dispenser is $8.85 \mathrm{~s}$ and 15,3 s respectively. Using delay program, the oil pumped out for $250 \mathrm{~mL}$ and $500 \mathrm{~mL}$ target volume need $5.75 \mathrm{~s}$ and $12 \mathrm{~s}$ delay time.
\end{abstract}

Keywords: Flow Sensor YF-S201, DC Pump, Contol Valve 


\section{PENDAHULUAN}

Minyak goreng merupakan salah satu dari sembilan bahan pokok yang dikonsumsi oleh seluruh lapisan masyarakat. Minyak goreng adalah salah satu kebutuhan pokok masyarakat Indonesia dalam rangka pemenuhan kebutuhan sehari-hari. Salah satu jenis minyak goreng adalah minyak goreng curah (Maisyarah, Pratiwi, \& Sutopo, 2014). Permintaan akan minyak goreng di pasaran cukup tinggi, terutama pada kondisi-kondisi tertentu seperti hari raya. Untuk mengendalikan harga minyak goreng, biasanya pemerintah melakukan operasi pasar. Umumnya pemerintah operasi pasar akan membeli minyak goreng curah (dalam bentuk drum atau cirigen) yang kemudian dikemas dengan kemasan $250 \mathrm{~mL}$ dan $500 \mathrm{~mL}$ karena adanya adanya larangan peredaran minyak goreng curah (Anggreani \& Adiwijaya, 2017). Pengemasan minyak juga dibutuhkan oleh distributor kemasan $250 \mathrm{~mL}$ atau $500 \mathrm{~mL}$.

Selama ini, untuk mengemas minyak goreng kedalam kemasan-kemasan tersebut dilakukan secara manual menggunakan takaran/timbangan konvensional. Cara ini kurang efisien dan dapat mempengaruhi kualitas dari minyak goreng karena kontaminasi dengan tangan dan udara terbuka. Alat otomatis untuk mengukur dan mengemas langsung minyak dalam kemasan sudah banyak jual namun dengan harga yang mahal dan spesifikasi industri. Menanggulangi hal tersebut, munculah ide untuk menciptakan sebuah alat yang dapat menyimpan dan mengeluarkan minyak goreng dengan volume tertentu. Alat ini didesain agar memiliki mobilitas yang tinggi sehingga dapat mudah di pindahkan dan digunakan untuk menghasilkan efisiensi dan konsistensi takaran.

Desain alat ini serupa dengan dispenser. Pada alat ini akan ditambahakan sistem otomasi untuk menentukan volume keluaran dari minyak goreng. Dispenser minyak ini juga akan dilengkapi pompa untuk mendorong minyak keluar dan sensor flowsensor untuk mengukur volume minyak yang keluar. Sedangkan pada bagian keluaran akan dipasang sebuah katup elektronik yang akan menggantikan fungsi dari kran. Dengan membuat sistem dispenser minyak goreng otomatis digarapkan dapat memudahkan pendistribusian/penjualan minyak goreng dengan tetap menjaga kuaitas minyak goreng yang takar.

\section{MATERIAL DAN METODE}

Metode yang digunakan pada perancangan sistem otomasi dispenser minyak ini dengan modifikasi dari metode prototype yaitu identifikasi kebutuhan dan kegunaan, proses perencanaan, simulasi dan pengukuran, implementasi, serta evaluasi dan dokumentasi (Purnomo, 2017). Identifikasi kebutuhan dan kegunaan dilakukan pada awal proses penelitian untuk mengetahui parameter dan spesifikasi yang dibutuhkan dispenser minyak goreng. Beberapa spesifikasi yang harus terpenuhi adalah dispenser harus mobile (dapat dipindahkan), mampu menampung $50 \mathrm{Kg}$ minyak goreng dan memiliki dua pilihan takaran yakni $250 \mathrm{~mL}$ dan $500 \mathrm{~mL}$.

Dari spesifikasi diatas, dirancanglah sebuah sistem otomasi yang sesuai. Proses selanjutnya yaitu perancangan sistem otomasi. Pada tahap ini, terdapat dua output antara lain desain dan alur dari sistem otomasi serta penentuan komponenkomponen yang akan digunakan seperti sensor dan aktuator. Agar dispenser mudah dipindahkan, daya yang digunakan adalah accu. Pengukuran minyak yang keluar dari dispenser menggunakan sebuah flowsensor. Sebuah pompa elektrik digunakan untuk mendorong minyak dari penampungnya.

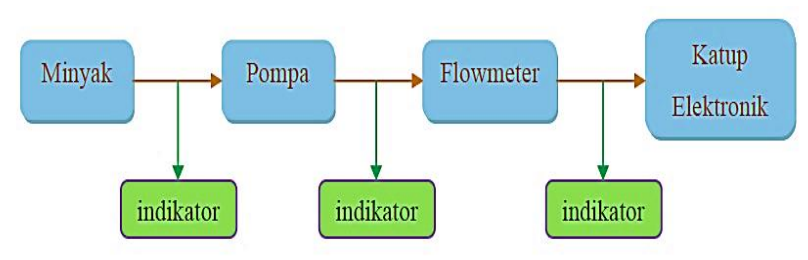

Gambar 1. Diagram Alir Sistem Otomasi pada Dispenser Minyak.

Gambar 1 menunjukkan diagram alir dari sistem otomasi pada dispenser minyak goreng. Setelah proses perancangan sistem selesai, tahap berikutnya adalah simulasi dan pengukuran. Simulasi sistem dilakukan dengan cara mengassembly komponenkomponen dari hasil perancangan dengan programnya. Tahap ini dilakukan untuk mengetahui apakah hasil perancangan sudah sesuai dengan spesifikasi yang diinginkan. Selain itu, percobaan dan pengukuran dilakukan dalam tahap ini untuk mendapat hasil/takaran yang sesuai sebelum sistem diimplementasikan pada dispenser minyak. Tahap terakhir adalah evaluasi.

\subsection{Vikositas Minyak Curah}

Hasil pengukuran minyak curah dan minyak kelapa sawit dari penelitian (Yusibani, Hazmi, \& Yufita, 2017) yang dilakukan pada $29^{\circ} \mathrm{C}, 1 \mathrm{~atm}$ ketika digunakan secara berulang sebanyak 2-10 kali didapatkan nilai vikositas minyak curah yang ditunjukkan pada Tabel 1. 
Tabel 1. Hasil Pengukuran Vikositas Minyak Curah

\begin{tabular}{|c|c|c|}
\hline No & $\begin{array}{c}\text { Perulangan } \\
\text { (kali) }\end{array}$ & $\begin{array}{c}\text { Vikositas Minyak } \\
\text { Curah }(\boldsymbol{\mu P a s})\end{array}$ \\
\hline 1 & 2 & $1656,02 \pm 189$ \\
\hline 2 & 4 & $1660,75 \pm 128$ \\
\hline 3 & 6 & $1699,22 \pm 134$ \\
\hline 4 & 10 & $1721,62 \pm 155$ \\
\hline
\end{tabular}

Dari Tabel 1 dan Gambar 2, didapat rata rata vikositas minyak curah rata-rata yang digunakan dalam penelitian ini adalah $1684,40 \mu$ Pas.

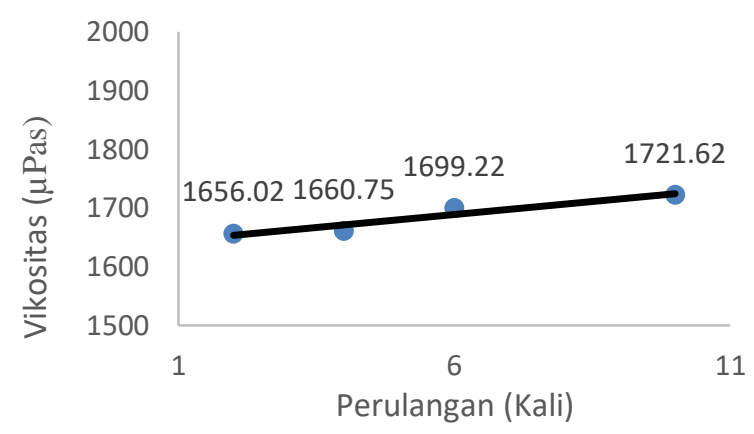

Gambar 2. Grafik Vikositas Minyak Curah

\subsection{Komponen Perangkat Keras}

Dispenser otomatis ini terdiri dari beberapa perangkat keras utama seperti Arduino uno, Flow sensor YF-S201, Pompa 12/24V dan Selenoid Valve. Berikut ini adalah penjelasan tentang sepesifikasi dari perangkat keras yang digunakan.

\subsubsection{Flow Sensor YF-S201}

Flowsensor terdiri dari katup plastik, rotor air, dan sebuah sensor hall-effect. Sensor ini memiliki keakuratan yang baik karena frekuensi pulsa Hall Effect memiliki hubungan linier dengan jumlah (volume) fluida yang melintasi penampang sensor sehingga memungkinkan flowsensor untuk digunakan dalam tujuan pengukuran akurasi dan presisi tinggi. Gambar 3 merupakan bentuk dari flowsensor YF-S201 (Lalnunthari \& Thanga, 2018).

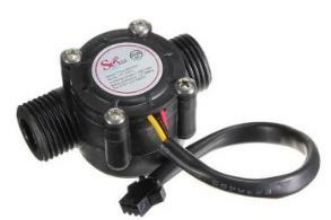

Gambar 3. Flow Sensor YF-S201

Karakteristik frekuensi berbanding jumlah fluida yang melintasi sensor dapat dilihat pada Gambar 4 dan Tabel 2. Gambar 4 merupakan grafik hubungan antara frekuensi dan debit fluida yang melewati penampang sensor (WikiSeeed Studio, 2013).

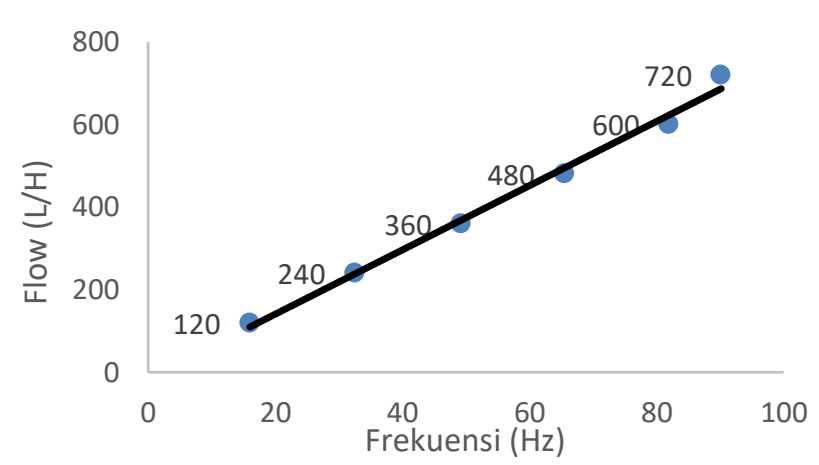

Gambar 4. Grafik Karakteristik Flow Sensor YFS201

Tabel 2. Data Flow Range vs Frekuensi Flow Sensor YF-S201

\begin{tabular}{|c|c|c|c|}
\hline No & Flow (L/H) & $\begin{array}{c}\text { Frekuensi } \\
(\mathbf{H z})\end{array}$ & \multirow{2}{*}{$\begin{array}{c}\text { Error } \\
\text { Range }\end{array}$} \\
\hline 1 & $120 \mathrm{~L} / \mathrm{H}$ & 16 & \multirow{1}{*}{ \pm 10} \\
\hline 2 & $240 \mathrm{~L} / \mathrm{H}$ & 32,5 & \multirow{2}{*}{ \pm 10} \\
\hline 3 & $360 \mathrm{~L} / \mathrm{H}$ & 49,3 & \\
\hline 4 & $480 \mathrm{~L} / \mathrm{H}$ & 65,5 & \\
\hline 5 & $600 \mathrm{~L} / \mathrm{H}$ & 82 & \\
\hline 6 & $720 \mathrm{~L} / \mathrm{H}$ & 90,2 & \\
\hline
\end{tabular}

Dari Gambar 4 dan Tabel 2 diketahui bahwa karakteristik frekuensi yang dihasilkan flowsensor linear terhadap jumlah fluida yang lewat.

\subsubsection{Pompa FB-12/24V dan Selonid Valve}

Pompa yang digunakan dalam penelitian ini adalah model pompa diafragma model FB-12/24V dengan power DC sebesar 12-24 VDC dengan Power 140W-160W (Hydrotherm Engineering Services, 2020). Pompa ini memiliki spesifikasi Flow rate sebesar 40 L/H dengan Rpm sebesar 2800. Gambar 5 merupakan gambar transfer pump yang dipakai dalam penelitian ini.

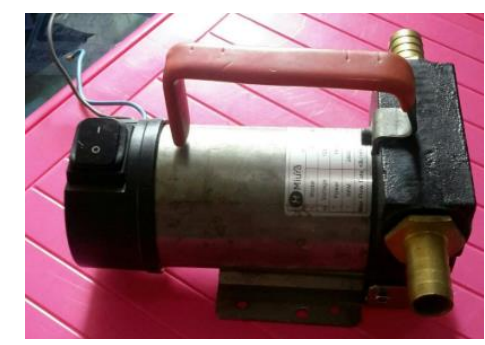

Gambar 5. Muira 12 VDC Transfer Pump

Gambar 6 adalah solenoid valve yang digunakan dalam penelitian ini, solenoid ini bekerja ketika diberi tengangan 12 VDC, ukuran orifice yang 
disesuaikan dengan pipa aliran minyak goreng (Brass, 2020).

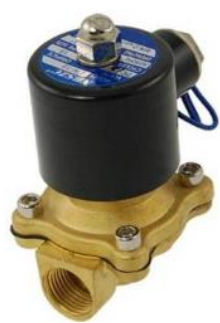

Gambar 6. Selenoid Valve

\subsection{Pembuatan Perangkat Keras}

Untuk mendukung sistem otomasi pada dispenser minyak goreng, maka pada penelitian ini dibuat sebuah panel kontrol dan indikator seperti yang ditunjukkan pada Gambar 7 berikut.

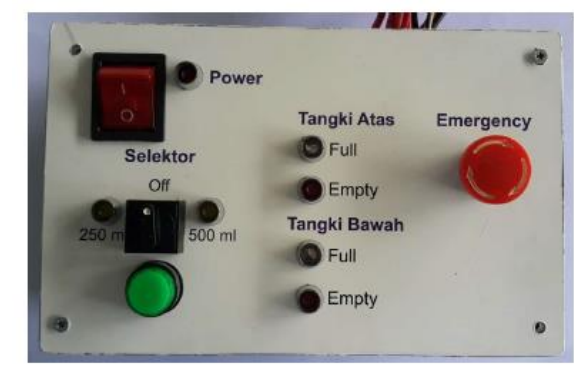

Gambar 7. Kontrol Panel Sistem Panel

Kontrol Panel terbuat dari material plastik dengan bagian atas menggunakan akrilik. Seperti yang terlihat pada Gambar 7, terdapat selektor keluaran pada panel untuk memilih volume minyak yang keluar dari dispenser. Selain tombol pilihan selektor, terdapat pula tombol power dan tombol emergency yang berfungsi sebagai pengaman jika teradi kegagalan sistem. Terdapat pula beberapa indikator led yang terdapat pada panel. Indikator ini memiliki fungsi sebagai informasi bagi pengguna dispenser untuk mengetahui kapan harus mengganti atau mengisi ulang minyak pada penampung.

Panel tersebut juga berisi sebuah mikrokontroller sebagai pemproses sistem otomasi dan dua buah relay yang akan mengkatifkan pompa dan valve elektronik.

\section{HASIL DAN PEMBAHASAN}

\subsection{Pengujian Flow Sensor}

Pengujian dilakukan terhadap respon sensor flowsensor YF-S201. Data yang dihasilkan oleh sensor MPU6050 akan diambil dan diproses oleh mikrokontroler arduino uno. Kemudian setelah diproses hasilnya akan ditampilkan menggunakan software serial monitor (L. Chen, J. Zhang, 2018).
Pengujian ini dilakukan untuk mengetahui nilai pembacaan sensor flowsensor saat volume keluaran minyak $250 \mathrm{~mL}$ dan $500 \mathrm{~mL}$. Tabel 3 berikut merupakan data dai pembacaan sensor flowsensor menggunakan serial 6 monitor. Pengujian sensor dilakukan menggunakan minyak goreng dan pada mekanik dispenser.

Tabel 3. Pengujian Pembacaan Sensor Flowsensor

\begin{tabular}{|c|c|c|c|c|c|}
\hline \multirow{2}{*}{$\begin{array}{c}\text { Pengisian Minyak } \\
(\mathbf{m L})\end{array}$} & \multicolumn{4}{|c|}{$\begin{array}{c}\text { Frekuensi Keluaran } \\
\text { Sensor (Hz) pada } \\
\text { Pengujian Ke- }\end{array}$} \\
\cline { 2 - 6 } & $\mathbf{1}$ & $\mathbf{2}$ & $\mathbf{3}$ & $\mathbf{4}$ & $\mathbf{5}$ \\
\hline 250 & 24 & 25 & 23 & 25 & 25 \\
\hline 500 & 34 & 37 & 38 & 36 & 35 \\
\hline
\end{tabular}

Pada Tabel 3, ditampilkan hasil pengujian sebanyak 5 kali pengujian untuk pembacaan aliran minyak goreng dengan 2 volume berbeda yaitu 250 $\mathrm{mL}$ dan $500 \mathrm{~mL}$. dapat digambarkan dengan grafik pada Gambar 8.

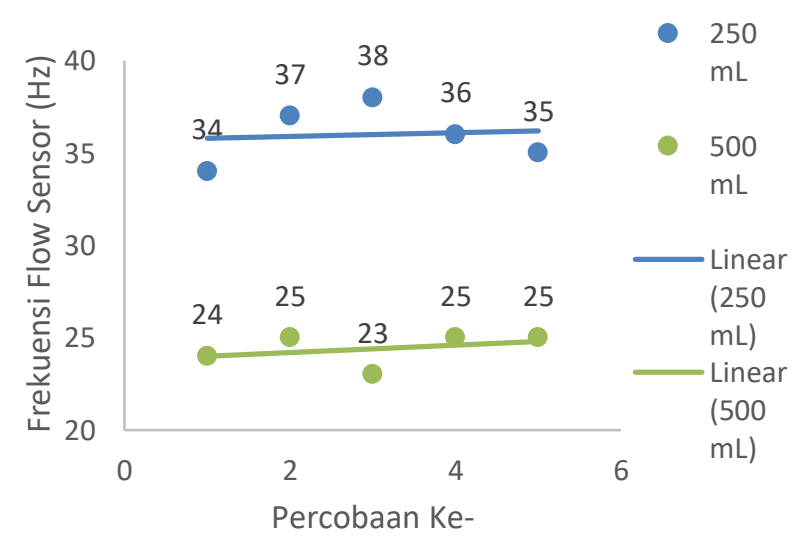

Gambar 8. Pengujian Pembacaan Sensor

Flowsensor pada $250 \mathrm{~mL}$ dan $500 \mathrm{~mL}$

Dari hasil Grafik pada Gambar 8 pengujian pembacaan flowsensor, maka untuk volume $250 \mathrm{~mL}$ digunakan data 25 pulsa sedangkan pada volume $500 \mathrm{~mL}$ menggunakan set 40 pulsa.

\subsection{Pengujian Waktu Pengeluaran Dispenser Minyak}

Pengujian pengukuran terhadap waktu pengisian dilakukan pada volume $250 \mathrm{~mL}$ dan $500 \mathrm{~mL}$. Tabel 4 berikut merupakan data waktu yang dibutuhkan untuk mengeluarkan minyak pada volume $250 \mathrm{~mL}$ dan $500 \mathrm{~mL}$. 
Tabel 4. Waktu Pengeluaran Dispenser Minyak

\begin{tabular}{|c|c|c|c|c|}
\hline $\begin{array}{c}\text { Pengeluaran } \\
\text { Minyak } \\
(\mathbf{m L})\end{array}$ & \multicolumn{4}{|c|}{$\begin{array}{c}\text { Lama Pengeluaran Minyak } \\
\text { (sekon) }\end{array}$} \\
\cline { 2 - 5 } & $\mathbf{1}$ & $\mathbf{2}$ & $\mathbf{3}$ & $\mathbf{4}$ \\
\hline 250 & 8,71 & 8,75 & 8,92 & 8,85 \\
\hline 500 & 15,45 & 15,31 & 15,24 & 15,21 \\
\hline
\end{tabular}

Pada pengujian ini untuk dapat mengeluarkan minyak dengan volume $250 \mathrm{~mL}$ dibutuhkan waktu rata-rata 8,8 detik sedangkan untuk volume $500 \mathrm{~mL}$ dibutuhkan waktu rata-rata 15,30 detik. Gambar 9 Menunjukkan Grafik Waktu pengeluaran pada dispenser minyak untuk 4 percobaan yang berbeda dari data Tabel 4 karakteristik dari pompa terlihat linear.

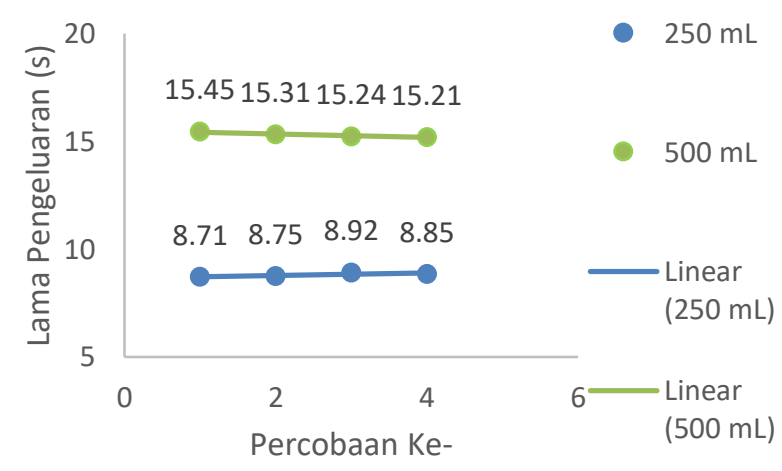

Gambar 9. Waktu Pengeluaran Dispenser Minyak Volume $250 \mathrm{~mL}$ dan $500 \mathrm{~mL}$

Percobaan ketiga dilakukan pengujian akurasi dan konsistensi dari keluaran minyak goreng. Pada pengujian ini keluaran minyak goreng tidak bisa konsistem baik pada $250 \mathrm{~mL}$ maupun $500 \mathrm{~mL}$. hal ini dikarenakan aliran yang mengalir pada flowsensor tidak stabil dengan tekanan yang kecil. Sehingga dilakukan pengujian keluaran volume tanpa menggunakan flowsensor dan hanya menggunakan delay.

Tabel 5 menunjukan volume keluaran minyak tanpa menggunakan flowsensor dan hanya menggunakan delay.

Tabel 5. Pengukuran Menggunakan Program

\begin{tabular}{|c|c|c|c|c|}
\hline \multicolumn{1}{|c|}{$\begin{array}{c}\text { Pengis } \\
\text { ian } \\
(\mathbf{m L})\end{array}$} & $\begin{array}{c}\text { Del } \\
\text { ay } \\
(\mathbf{s})\end{array}$ & $\begin{array}{c}\text { Katup } \\
\text { Tertut } \\
\text { up }\end{array}$ & $\begin{array}{c}\text { Miny } \\
\text { ak } \\
\text { Berhe } \\
\text { nti } \\
\text { Kelua } \\
\text { r }\end{array}$ & $\begin{array}{c}\text { Kekurangan/Kel } \\
\text { ebihan dari } \\
\text { Target }\end{array}$ \\
\hline \multirow{2}{*}{500} & 11 & 380 & 460 & -40 \\
\cline { 3 - 5 } & 12.5 & 430 & 530 & +70 \\
\cline { 3 - 5 } & 12 & 420 & 510 & +10 \\
\hline
\end{tabular}

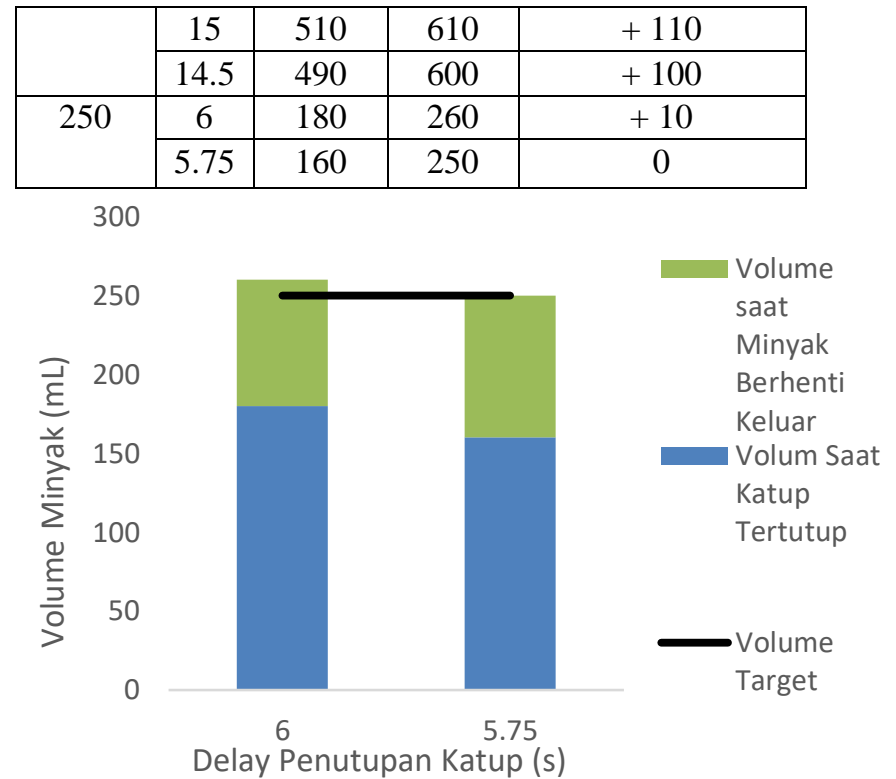

Gambar 10. Pengukuran Volume Minyak Keluar Menggunakan Program Delay untuk target $250 \mathrm{~mL}$

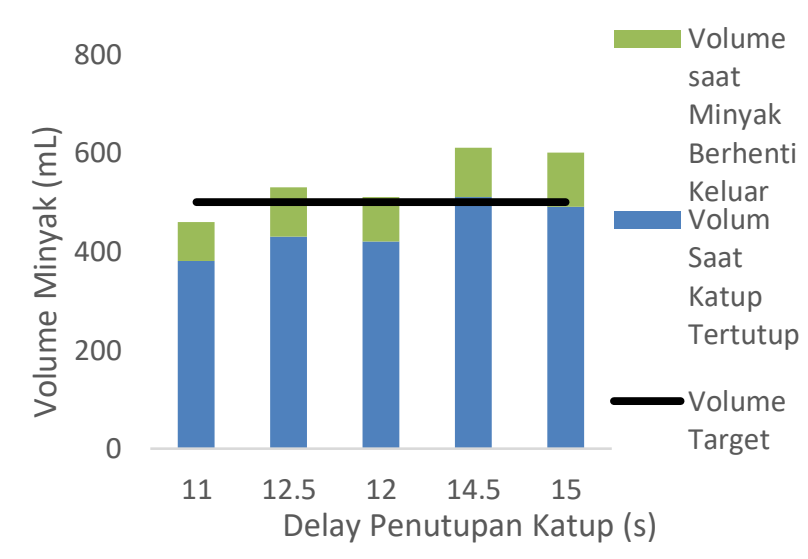

Gambar 11. Pengukuran Volume Minyak Keluar Menggunakan Program Delay untuk target $500 \mathrm{~mL}$

Untuk target volume $250 \mathrm{~mL}$, delay terbaik yang menghasilkan ketepatan pengeluaran volume ada pada delay sebesar $5,57 \mathrm{~s}$ dengan pengeluaran volume minyak real sebesar $250 \mathrm{~mL}$ seperti terlihat pada Gambar 10.

Dari Gambar 11, delay terbaik yang menghasilkan ketepatan pengeluaran volume minyak target $500 \mathrm{~mL}$ ada pada delay sebesar $12 \mathrm{~s}$ dengan pengeluaran volume minyak real sebesar 510 $\mathrm{mL}$.

\section{PENUTUP}

\section{Kesimpulan}

Dari hasil pengujian flowsensor, pengujian waktu pengeluaran dan pengukuran dengan sistem delay didapatkan beberapa kesimpulan, diantarnya : 
1. Pembacaan flowsensor menunjukkan hasil frekuensi rata-rata yang sama yaitu sebesar $25 \mathrm{~Hz}$ untuk pengisian $250 \mathrm{~mL}$ dan $35 \mathrm{~Hz}$ untuk pengisian minyak $500 \mathrm{~mL}$.

2. Waktu yang diperlukan untuk mengeluarkan minyak $250 \mathrm{~mL}$ dari dispenser sebesar $8,85 \mathrm{~s}$ dan $15,3 \mathrm{~s}$ untuk mengeluarkan minyak $500 \mathrm{~mL}$.

3. Dengan program delay dapat diperbaki nilai keluaran minyak, untuk volume target $250 \mathrm{~mL}$ diperlukan delay sebesar 5,75 s dan untuk volume targer keluaran $500 \mathrm{~mL}$ diperlukan delay sebesar $12 \mathrm{~s}$.

\section{DAFTAR PUSTAKA}

Anggreani, F., \& Adiwijaya, M. (2017). Analisis Pengaruh Marketing Mix Terhadap Keputusan Pembelian Minyak Goreng Letizia Di Pandaan. Agora, 5(1).

Brass. (2020). Brash - 2 Way General Purpose Solenoid Valves. Retrieved from https://www.electricsolenoidvalves.com/1-2$12 \mathrm{v}$-dc-electric-brass-solenoidvalve/\#downloads

Hydrotherm Engineering Services. (2020). 12V/24V Diesel Fuel Transfer Pump. Retrieved from https://www.indiamart.com/proddetail/12v$24 \mathrm{v}$-diesel-fuel-transfer-pump19002796933.html

L. Chen, J. Zhang, Y. W. (2018). 2018 2nd IEEE Advanced Information Management,Communicates,Electronic and Automation Control Conference(IMCEC 2018). (Imcec), 1783-1787.

Lalnunthari, J., \& Thanga, H. H. (2018). Dependence of hall effect flow sensor frequency on the attached inlet and outlet pipe size. 2017 IEEE International Conference on Consumer Electronics-Asia, ICCE-Asia 2017, 2018January, https://doi.org/10.1109/ICCEASIA.2017.8307842

Maisyarah, A., Pratiwi, A., \& Sutopo, W. (2014). Model Penentuan Operasi Pasar Untuk Mendukung Stabilisasi Harga Minyak Goreng Curah. 151-167.

Practical Data Acquisition for Instrumentation and Control Systems. (2003). Practical Data Acquisition for Instrumentation and Control Systems.

Elsevier. https://doi.org/10.1016/b978-0-7506-57969.x5000-9
Purnomo, D. (2017). Model Prototyping Pada Pengembangan Sistem Informasi. Jurnal Informatika Merdeka Pasuruan, 2(2), 54-61.

WikiSeeed Studio. (2013). YF-S201 Water Flow Sensor Datasheet. 1. Retrieved from http://www.seeedstudio.com/wiki/index.php? title=G1/2_Water_Flow_sensor\&action

Yusibani, E., Hazmi, N. Al, \& Yufita, E. (2017). Pengukuran Viskositas Beberapa Produk Minyak Goreng Kelapa Sawit Setelah Pemanasan Viscosity Measurement of Palm Cooking Oil Products After Heating. 09(01). https://doi.org/10.17969/jtipi.v9i1.6108 